\title{
Phytopathology
}

\section{Perceptions of Risk, Risk Aversion, and Barriers to Adoption of Decision Support Systems and Integrated Pest Management: An Introduction}

\author{
David H. Gent, Erick De Wolf, and Sarah J. Pethybridge
}

First author: U.S. Department of Agriculture-Agricultural Research Service, Forage Seed and Cereal Research Unit, and Oregon State University, Department of Botany and Plant Pathology, Corvallis, OR 97331; second author: Kansas State University, Department of Plant Pathology, Manhattan 66506-5502; and third author: Botanical Resources Australia-Agricultural Services Pty Ltd.,

Ulverstone, Tasmania 7315, Australia.

\begin{abstract}
Gent, D. H., De Wolf, E. D., and Pethybridge, S. J. 2011. Perceptions of risk, risk aversion, and barriers to adoption of decision support systems and integrated pest management: An Introduction. Phytopathology 101:640-643.

Rational management of plant diseases, both economically and environmentally, involves assessing risks and the costs associated with both correct and incorrect tactical management decisions to determine when control measures are warranted. Decision support systems can help to inform users of plant disease risk and thus assist in accurately targeting events critical for management. However, in many instances adoption of these systems for use in routine disease management has been perceived as slow. The under-utilization of some decision support systems is likely due to both technical and perception constraints that have not been addressed adequately during development and implementation phases. Growers' perceptions of risk and their aversion to these perceived risks can be reasons for the "slow" uptake of decision support systems and, more broadly, integrated pest management (IPM). Decision theory provides some tools that may assist in quantifying and incorporating subjective and/or measured probabilities of disease occurrence or crop loss into decision support systems. Incorporation of subjective probabilities into IPM recommendations may be one means to reduce grower uncertainty and improve trust of these systems because management recommendations could be explicitly informed by growers' perceptions of risk and economic utility. Ultimately though, we suggest that an appropriate measure of the value and impact of decision support systems is grower education that enables more skillful and informed management decisions independent of consultation of the support tool outputs.
\end{abstract}

Corresponding author: D. H. Gent; E-mail address: gentd@onid.orst.edu

doi:10.1094/PHYTO-04-10-0124

This article is in the public domain and not copyrightable. It may be freely reprinted with customary crediting of the source. The American Phytopathological Society, 2011
Agricultural production involves some level of risk of crop loss due to plant diseases. Rational management of plant diseases, both economically and environmentally, involves assessing these risks and the costs associated with both correct and incorrect management decisions to determine when control measures are warranted. Given these motivations, one of the primary objectives of epidemiology has been risk assessment to inform and improve strategic and tactical plant disease management decision making (25). Risk prediction for tactical disease management decisions can take several forms that could include subjective assessments based on a producer's experience or intuition, sampling, or a quantitative assessment of disease occurrence or intensity formalized in a decision support system. We focus our discussion on quantitative prediction of disease or disease risk by means of decision support systems, a term we will use interchangeably with "predictive system," which is one form of decision support $(14,20,23)$. However, decision support systems are used by producers and other practitioners who make subjective assessments regarding the risk of crop losses based on factors beyond the classical view of the disease triangle. We therefore also illustrate linkages to sociological aspects of risk assessment and aversion that may affect how readily (or if) a decision support system is adopted, or in what manner it is used to inform pest management decisions.

Development of a decision support system is based on the rationale that pest and disease development follow predictable life cycles and that if key parameters are monitored, predictions can accurately target events critical for management. Thus their usage should aid in implementing control measures that are economically and ecologically sound. There is a general recognition that many producers have not adopted decision support systems as part of their IPM $(7,11,25)$, although several examples of decisions systems that have been widely implemented provide insights into characteristics of successful systems (Box 1; 4,22). In reference to decision support systems, in 1984 Seem and Russo (20) noted, "...remarkably few of these procedures have been implemented in growers' management programs." Six years later, Campbell and Madden (1) suggested that disease forecasting 
would become more valuable to producers as the cost of pesticides increased, pesticide registrations were lost, and regulatory constraints increased. Nearly two decades after this prediction, one could argue that few forecasting systems are routinely utilized at the farm level relative to the number of decision support systems that have been developed. Magarey et al. (10) stated directly that many systems "never work," are "never used," or are "never finished." For systems that are often considered "successful", adoption rates still can be near or less than $50 \%$. Given the finite resources available for IPM research and development and the costs associated with decision support system design and validation (3), there is a clear motivation to understand why and how growers adopt or reject these tools as components of IPM systems.

Because of the central roles risk aversion and management may play in use of decision support systems and, more broadly, IPM in general, the symposium "Perceptions of Risk, Risk Aversion, and Barriers to Adoption of Decision Support Systems and IPM" was held at the Annual Meeting of The American Phytopathological Society (APS) from 31 July to 5 August 2009 in Portland. The symposium was sponsored by the APS subject matter committees Crop Loss Assessment and Risk Evaluation, Epidemiology, and Integrated Plant Disease Management. Other factors beyond risk assessment and aversion clearly interact to affect adoption (10, 23,24 ) but were beyond the scope of this symposium and cannot be presented adequately within the confines of this paper.

\section{UTILIZATION OF DECISION SUPPORT SYSTEMS AND GROWER RISK PERCEPTIONS}

The under-utilization of some decision support systems is likely due to technical constraints and growers' attitudes that have not been addressed adequately during development and implementation phases. These constraints have been presented by multiple authors $(1,3,8,10,20)$. The technical constraints may include accuracy and accessibility of current and forecasted meteorological data, imprecise methods for spatial interpolation of the observed and forecasted data, translation of the data into environmental inputs needed by pest or disease models, and the difficulty in accurately estimating disease risk in some pathosystems.

Grower perception of and attitudes towards pest prediction, and the risks that they perceive they may be exposed to with their use, may have the greatest impact on whether a predictive system is utilized by IPM practitioners (1). Often these systems are designed and marketed as tools to reduce or optimize pesticide inputs and thus enhance economic competiveness. The United Nations Food and Agriculture Organization suggests that adoption of an innovation is unlikely unless it offers, approximately, a 2:1 or greater financial advantage over existing practices-a ratio that requires highly accurate predictive systems which may not be achieved for some high value crops (5). Intended users of these systems tend to be risk averse and seek to minimize both average management costs and large variations in income $(5,21)$, creating a potential disconnect between the objectives of the developer and intended end user.

Wearing (24) found that cost savings provided an incentive for IPM adoption, but also found that one of the most important obstacles to adoption was the perception of financial risk from not spraying preventatively. He stated, "It is very important, therefore, that IPM does not increase this risk or the farmer's perception of it." An individual's degree of belief in the truth of a particular proposition is termed a "subjective probability", and consequently subjective probabilities exist only in empirical form. Such probabilities are subjective in the sense that they reflect an individual's assessment based on their knowledge, opinions, or intuition. For instance, one grower may feel that there is a small chance of an economically damaging disease outbreak without prophylactic treatment, but another grower may believe that a prophylactic (and perhaps unnecessary) pesticide application is required. The latter grower likely feels more compulsion to act on their subjective probability of crop loss due to pest outbreak. As stated by Yuen and Hughes (26) "...calculations and logic remain a theoretical discussion when it comes to predicting human behavior, and acceptance or rejection of decision support systems. What matters is not the true prior [probability] (that is established via historical data, surveys, or other objective means) but the perceived prior of the decision maker." Incorporation of subjective probabilities of disease risk into predictive systems (2) could partially address this issue by including information on decision maker's reactions to different risky situations (26). McRoberts et al. (12) present information on how grower perceptions of and aversion to risk can influence their pest management decision making, and provide examples from decision theory to evaluate the utility of predictive systems under varying scenarios of disease prevalence. Pfender et al. (17) provide examples and discuss the difficulty of quantifying uncertainty and risk with more complex weather-driven decision support systems.

\section{THE PURPOSE OF DECISION SUPPORT SYSTEMS: MORE INFORMED MANAGEMENT DECISIONS}

Although examination of many decision support systems may indicate a low level of sustained use by growers, due in part to their perceptions and avoidance of risk, we propose that the

\section{BOX 1}

Adoption of the Gubler-Thomas grape powdery mildew risk index. "Successful" decision support systems provide some insights into key factors that may influence the speed and level of adoption. The Gubler-Thomas grape powdery mildew index (6), for example, is one of the more broadly implemented decision support systems developed, with derivations applied in several other crops (22). The index provides simple and intuitive recommendations for determining appropriate fungicide application intervals. A recent survey of California wine grape growers indicated that adoption of this index has occurred and increased over the past decade, a much longer-term view of adoption than what is often considered, with about $50 \%$ of growers self-reporting as using the index heavily, often, or sometimes (9). Users of the system tended to be more experienced managers or producers that operated larger farms, which they were more likely to rent, with greater yields and value of production compared with non-users. In this system, $87 \%$ of all growers (users and non-users) reported that they were never or rarely constrained by spray equipment availability to make fungicide applications. Many of the nonadopters cited their preference for a set spray schedule as the primary reason for not using the index, although the reasons for this preference are not entirely clear. For adopters, the driving factor for use of the index was better disease control, which appears to be tightly linked to reducing risk exposure. 
pedagogic aspects of these systems remain important. Implicit in many discussions on use of these systems, including those cited above $(10,20)$, is often a definition of "success" based on adoption rates or sustained use of a system by producers. In reference to expert systems, one form of decision support, Travis and Latin (23) stated more directly "...the success of a system depends on the degree of adoption by users." They also indicated the number of times a system is accessed and the amount of time growers spend using a system can be interpreted as one aspect of adoption. Within the funding constraints of most projects, easily quantified metrics of adoption often are tallied, such as website traffic, model runs per season, or percentage of growers self-reporting as using the systems. Are these the best gauges of adoption and success given the complex nature of crop management and numerous sources of information growers must consider and integrate? We suggest that many decision support systems have a natural lifecycle of development, verification, application and, in many cases, atrophy due in part to grower education and internalization of the underlying risk factors quantified in a decision support system. Lybbert and Gubler (9), for example, found 15\% of growers reported stopping their use of the Gubler-Thomas grape powdery mildew index, which may be related to some degree to their internalization of the index rules. Given this cycle, it seems unlikely that long-term deployment and sustained use of predictive systems is the best metric of success. The pedagogic value of decision support systems and the idea of a useful, but limited lifespan were noted among early examples. Zadoks (27) reported that one of the main reasons Dutch farmers gave for stopping their use of the EPIPRE decision support system in wheat was that they had learned how the system arrived at its recommendations so they no longer needed it to make correct decisions.

Thus, a focus on usage or sustained usage of a decision support system may ignore how growers integrate the outputs in their decision making and the importance of the grower education that these systems provide: a broader perspective on the purposes of predictive systems is needed. If the objective of a decision support system is to enable more skillful and informed decision making by growers, not simply use of the tool, then perhaps an appropriate question to judge success is, "Are growers making correct management decisions more often than before the predictive system was developed?" Within this context "adaptive implementation" or "re-invention", in which an innovation is modified to fit the user (18), would be considered and included in our appraisal of success. This question also presumes we know or can determine what the "correct" management decision is or, more likely, the correct sequence of multiple management decisions needed for optimum disease control, economic return, or some other desired outcome. This is discussed in detail by Pfender et al. (17).

Participatory educational approaches (19) appear to be the most appropriate for addressing this success appraisal question, and may lead researchers to a broader perspective on integrated disease and pest control. Box 2 presents an instructive case study of ray blight disease of pyrethrum. Participatory approaches also force researchers to recognize that their goals may not align with those of their clientele (13); some decisions support systems may

\section{BOX 2}

Diffusion and adoption of ray blight management strategies in Australia. An example of a rapid adoption of a disease management program is the case of ray blight (caused by Phoma ligulicola) in pyrethrum in Tasmania, Australia (16). This was partly due to the severity and rapid onset of ray blight epidemics, resulting in substantial losses to growers and the industry. In many cases, entire crops were terminated prior to the first harvest of the field. An extensive research program was initiated, primarily focusing on the identification of efficacious fungicides and gaining a more comprehensive understanding of the epidemiology of the disease. In the first 2 years of this study, a two to three fungicide application program was developed that considered resistance groupings of other products used later in the production cycle and the cost-benefits of the program. To facilitate the uptake of these new recommendations by growers, strip trials were conducted within numerous fields which comprised approximately $70 \%$ of the total production area in those years. Within 2 years, the new recommendations were adopted by over $90 \%$ of pyrethrum growers. This was attributed to the implementation of a participatory approach to formulation and extension of these findings based on aspects of diffusion theory (18). Rodgers (18) described the characteristics of successful innovations. For the ray blight case, these were as follows: (i) multimodal communication of information, including field days, workshops, and extensive individual growers and field staff discussions; (ii) "relative advantage" of the disease management recommendations by grower trialing in their own fields and the provision of specific cost-benefit information; (iii) direct observability of the treatments by cooperating growers, which fostered communication of the treatment effectiveness to other growers; and (iv) the compatibility of the disease management recommendations to growers' current practices. From 2004 to 2009, at least $98.5 \%$ of growers have adopted these new recommendations. Extension efforts have focused on reminding growers of the benefits of the fungicide program to ensure that adoption of these recommendations does not decline. Multiple delivery of the cost-effectiveness of this program message have included information presented in quarterly agronomic newsletters, and most importantly face-to-face communication of the message through the extensive field staff network which visits individual growers on a fortnightly basis. For this example, the strong interaction with the pyrethrum industry and grower participation was of paramount importance to achieving these levels of adoption in a short timeframe. Some aspects of the management program also have become compulsory for growers to produce for certain companies. Obligatory adoption of management tactics through production contracts presents another means to accelerate and maintain adoption of practices. In these instances, engaging contractors may be the most direct means to affect pest management decisions by the allied growers.

Concerns of fungicide over-use, following implementation of the program, lead to the identification of the site-specific risk factors to better rationalize tactical disease management decisions. The objective of this study was to assist growers in making correct decisions concerning the need for the final (third) fungicide application for this disease. An economic analysis of the optimum management-action threshold for a logistic regression model for estimation of the risk of severe epidemics indicated that the risk of a false negative prediction did not justify the use of the model unless disease prevalence was very low $(<0.2)$. Thus, the routine practice of applying a prophylactic third fungicide treatment appears to be economically justified unless a highly accurate disease risk model can be developed or conditions associated with low disease prevalence can be identified (15). 
not fit the needs of the intended users, which is a constraint to adoption and advancement of IPM (24). In the words of Wearing (24), "Indeed, lack of education of IPM developers about the perceptions of farmers is probably a much greater obstacle to implementation than the reverse." In short, IPM must "fit" the end user. Such a fit to local requirements is critical for designing successful decision support tools and IPM systems that are adopted by growers. As decision support tools continue to be developed and refined, greater emphasis on designing and implementing these tools with consideration to the characteristics of successful innovations (18) and grower perceptions of risk could help to increase the value of these tools for their intended endusers.

\section{ACKNOWLEDGMENTS}

The use of trade, firm, or corporation names in this publication is for the information and convenience of the reader. Such use does not constitute an official endorsement or approval by the United States Department of Agriculture or the Agricultural Research Service of any product or service to the exclusion of others that may be suitable. Financial support was provided by USDA-ARS CRIS 5358-21000-035-00 and Kansas State University. We thank W. Mahaffee, N. McRoberts, B. Pfender, and C. Thomas for providing comments and suggestions on earlier drafts of this paper.

\section{LITERATURE CITED}

1. Campbell, L. C., and Madden, L. V. 1990. Introduction to Plant Disease Epidemiology. John Wiley and Sons, New York.

2. Carlson, G. A. 1970. A decision theoretic approach to crop disease prediction and control. Am. J. Agric. Econ. 52:216-223.

3. Crassweller, R. M., Travis, J. W., Heinemann, P. H., and Rajotte, E. G. 1993. The actual and potential future use of expert system in horticulture. Hortic. Technol. 3:203-205.

4. De Wolf, E. D., and Isard, S. A. 2007. Disease cycle approach to plant disease prediction. Annu. Rev. Phytopathol. 45:203-220.

5. Fabre, F., Plantegenest, M., and Yuen, J. 2007. Financial benefit of using crop protection decision rules over systematic spraying strategies. Phytopathology 97:1484-1490.

6. Gubler, W. D., Rademacher, M. R., Vasquez, S. J., and Thomas, C. S. 1999. Control of powdery mildew using the UC Davis powdery mildew risk index. Online. APSnet Feature Story, January 1999. The American Phytopathological Society, St. Paul, MN.

7. Knight, J. D. 1997. The role of decision support systems in integrated crop protection. Agric. Ecosyst. Environ. 64:157-163.

8. Krause, R. A., and Massie, L. B. 1975. Predictive systems: Modern approaches to disease control. Annu. Rev. Phytopathol. 13:31-47.
9. Lybbert, T. J., and Gubler, W. D. 2008. California wine grape growers' use of powdery mildew forecasts. Agric. Resour. Econ. Update 11:11-14.

10. Magarey, R. D., Travis, J. W., Russo, J. M., Seem, R. C., and Magarey, P. A. 2002. Decision support systems: Quenching the thirst. Plant Dis. 86: 4-14.

11. McCown, R. L. 2002. Changing systems for supporting farmers' decisions: Problems, paradigms, and prospects. Agric. Syst. 74:179-220.

12. McRoberts, N., Hall, C., Madden, L. V., and Hughes, G. 2011. Perceptions of disease risk: From social construction of subjective judgments to rational decision making. Phytopathology 101:654-665.

13. Pannell, D. J., Marshall, G. R., Barr, N., Curtis, A., Vanclay, F., and Wilkinson, R. 2006. Understanding and promoting adoption of conservation practices by rural landholders. Aust. J. Exp. Agric. 46:1407-1424.

14. Petersen, G. W., Day, R. L., Anthony, C. T., Pollack, J., and Russo, J. M. 1993. Importance of spatial variability in agricultural decision support systems. Pages 167-169 in: Proc. Soil Specific Crop Management. P. C. Robert, R. H. Rust, and W. E. Larson, eds. American Society of Agronomy, Madison, WI.

15. Pethybridge, S. J., Gent, D. H., Esker, P. D., Turechek, W. W., Hay, F. S., and Nutter, F. W., Jr. 2009. Site specific risk factors for ray blight in Tasmanian pyrethrum fields. Plant Dis. 93:229-237.

16. Pethybridge, S. J., Hay, F. S., Esker, P. D., Gent, D. H., Wilson, C. R., and Nutter, F. W., Jr. 2008. Diseases of pyrethrum in Tasmania: Challenges and prospects for management. Plant Dis. 92:1260-1272.

17. Pfender, W. F., Gent, D. H., Mahaffee, W. F., Coop, L. B., and Fox, A. D. 2011. Decision aids for multiple-decision disease management as affected by weather input errors. Phytopathology 101:644-653.

18. Rodgers, E. 2003. Diffusion of Innovations. 5th ed. Free Press, New York.

19. Röling, N., and Wagemakers, A. 1998. Facilitating Sustainable Agriculture: Participatory Learning and Adaptive Management in Times of Environmental Uncertainty. Cambridge University Press, Cambridge.

20. Seem, R. C., and Russo, J. M. 1984. Simple decision aids for practical control of pests. Plant Dis. 68:656-660.

21. Shtienberg, D. 2000. Modelling: The basis for rational disease management. Crop Prot. 19:747-752.

22. Thomas, C. S., Skinner, P. W., Fox, A. D., Greer, C. A., and Gubler, W. D. 2002. Utilization of GIS/GPS based information technology in commercial crop decision making in California, Washington, Oregon, Idaho, and Arizona. J. Nematol. 34:200-206.

23. Travis, J. W., and Latin, R. X. 1991. Development, implementation and adoption of expert systems. Annu. Rev. Phytopathol. 29:343-360.

24. Wearing, C. H. 1988. Evaluating the IPM implementation process. Annu. Rev. Entomol. 33:17-38

25. Yang, X. B. 2003. Risk assessment: Concepts, development and future opportunities. Online. Plant Health Progress doi:10.1094/PHP-20031113-02-RV.

26. Yuen, J. E., and Hughes, G. 2002. Bayesian analysis of plant disease prediction. Plant Pathol. 51:407-412.

27. Zadoks, J. C. 1988. EPIPRE, a computer-based decision support system for pest and disease control in wheat: Its development and implementation in Europe. Plant Dis. Epidemiol. 2:3-29. 